\title{
Democracia e Religião no discurso parlamentar de mulheres antifeministas e feministas ${ }^{1}$
}

\author{
Recebido em 15/05/2020, aprovado em 15/07/2020 \\ DOI: $10.30612 / m v t . v 7 i 12.11947$ \\ Bruna Quinsan Camargo ${ }^{2}$ \\ Raisa Cortez Rosado ${ }^{3}$
}

\section{RESUMO:}

O artigo objetivou identificar os argumentos mobilizados pelas deputadas federais no conflito sobre feminismo durante o ano de 2019 por meio do procedimento metodológico qualitativo da Análise de Conteúdo, a partir das categorias argumentativas "democracia”, "jurídico", "científico" e "religioso". Os materiais analisados foram as justificativas de proposiçóes e os discursos de deputadas federais antifeministas e feministas que disputam espaço e legitimidade no Estado. Os dados, que foram coletados na plataforma de monitoramento legislativo SigaLei e analisados com o auxílio do software NVivo, indicam a aceitação das hipóteses de que a mobilização antifeminista recorre a argumentos de ordem científica e jurídica, e não propriamente religiosos; e de que a linguagem da democracia é mobilizada para combater a perspectiva feminista de gênero em políticas públicas. Além disso, os dados indicam uma disputa em torno da concepção de democracia entre os dois grupos antagônicos e também sugerem que valores e concepçóes religiosas recebem uma camuflagem democrática, causando confusão e debilitação do caráter laico do Estado.

Palavras-chave: Antifeminismo. Religião e política. Democracia.

\section{Democracy and Religion in the parliamentary discourse of antifeminist and feminist women}

\section{ABSTRACT:}

This work aimed to identify the arguments mobilized by women members of the Chamber of Deputies in the conflict over feminism during 2019 through the qualitative methodological

1 Este artigo foi originalmente publicado em ROSADO, R. C. ; CAMARGO, B. Q. Democracia e Religião no Discurso Parlamentar de Mulheres Antifeministas e Feministas; 2019. In: DINIZ, S.; RIBEIRO, P. J. F. Atuaçáo parlamentar: ensaios sobre atividades legislativas na Câmara dos Deputados. São Carlos (SP): EDUFSCar - Universidade Federal de São Carlos, 2020.

2 Mestranda em Ciência Política (PPGPOL/UFSCar) e bolsista CAPES. Membra do Núcleo de Estudos sobre Democracia e Desigualdades: Políticas Públicas e Percepçóes Públicas (NEDEPP). E-mail: missquinsan@hotmail.com.

3 Graduanda em Ciências Sociais (UFSCar). E-mail: cortezraisa@gmail.com. 
procedure of Content Analysis, based on the argumentative categories "democracy", "juridical", "scientific" and "religious". The materials analyzed were proposition justifications and speeches of the anti-feminist and feminist deputies that dispute space and legitimacy in the state. The data, which were collected on the legislative monitoring platform SigaLei and analyzed with the aid of the software NVivo, indicates acceptance of the hypotheses that the antifeminist mobilization uses scientific and legal arguments, and not properly religious; and that the democracy language is mobilized to combat the feminist gender perspective in public policies. In addition, the data indicates a dispute over the conception of democracy between the two antagonistic groups, and also suggests that religious values and conceptions are given a democratic camouflage, causing confusion and weakening of the state's secular character.

Keywords: Antifeminism. Religion and Politics. Democracy.

\section{Democracia y religión en el discurso parlamentario de mujeres antifeministas y feministas}

\section{RESUMEN:}

El artículo tuvo como objetivo identificar los argumentos movilizados por las diputadas federales en el conflicto sobre el feminismo durante el año 2019 mediante el procedimiento metodológico cualitativo del Análisis de Contenido, a partir de las categorías argumentativas "democracia”, "jurídico", "científico" y "religioso". Los materiales analizados fueran las justificativas de proposiciones y los discursos de diputadas federales antifeministas y feministas que disputan el espacio y la legitimidad en el Estado. Los datos, recogidos en la plataforma de monitoreo legislativo SigaLei y analizados con la ayuda del software NVivo, indican la aceptación de las hipótesis de que la movilización antifeminista utiliza argumentos del orden científico y jurídico, y no propiamente religiosos; y que el lenguaje de la democracia es movilizada para combatir la perspectiva de género feminista en las políticas públicas. Además, los datos indican una disputa sobre la concepción de democracia entre los dos grupos antagonistas y también sugieren que los valores y las concepciones religiosas reciben un camuflaje democrático, causando confusión y debilitación del carácter laico del Estado.

Palavras Clave: Antifeminismo. Religión y política. Democracia.

\section{INTRODUÇÃO}

Não somos devedores de um grito de defesa aos Antônios, Pedros, Josés e tantas outras vítimas anônimas do famigerado empoderamento feminino, conceito doentio que monstros distorcidos [...] usam para justificar seus desígnios nocivos?

Deputada Federal Bia Kicis (PSL - RJ) 
O trecho mobilizado acima faz parte de um discurso da deputada federal Bia Kicis em que, para sustentar seu argumento de que o movimento LGBTQIA $+{ }^{4}$ demanda privilégios e censura, a deputada atrela a motivação do assassinato de uma criança, cometido pelas mães lésbicas, à teoria feminista sobre gênero, chamada no discurso de "ideologia de gênero".

"Ideologia de gênero", como sugere a pesquisadora Maria das Dores Campos Machado (2018), é uma categoria acusatória criada por teólogos, sacerdotes e cardeais de setores conservadores da igreja católica, com a finalidade de desqualificar a teoria feminista de gênero e frear o avanço dos movimentos feministas e LGBTQIA+. Tal terminologia foi adotada posteriormente por lideranças evangélicas conservadoras e por grande parte das outras forças que compóem a extrema-direita que se espalha pelo mundo, em especial as direitas emergentes na América Latina, local em que o feminismo se desenvolveu com movimentos de esquerda (Sagot, 2012) e que contava com uma maior organizaçáo feminista em conferências da ONU da década de 1990 (Corrêa, 2018).

O avanço da extrema-direita no Brasil pode ser verificado no crescimento da representação parlamentar de atores que se dizem abertamente de direita e que defendem calorosamente um conservadorismo moral, operando "em funçáo de avanços 'intoleráveis' em algumas das 'pautas progressistas' no Executivo, no Legislativo e no Judiciário" (Quadros e Madeira, 2018). O reconhecimento de direitos básicos de lésbicas, gays, bissexuais e população trans, bem como o enfrentamento às violências diversas sofridas por mulheres, pessoas negras e pessoas que desobedecem as normas cisgênera e heterossexual são exemplos de tais avanços considerados “intoleráveis” para esses grupos.

Diante de tal conflito entre atores progressistas e conservadores, que disputam espaço, poder e legitimidade no Estado e na sociedade, o presente artigo objetiva identificar os argumentos mobilizados pelas deputadas federais que compóem o campo da direita brasileira no enfrentamento ao feminismo durante o primeiro ano da atual legislatura (2019-2023) da Câmara dos Deputados. A análise de conteúdo de proposiçóes e de discursos das deputadas indica a aceitação das hipóteses de que a mobilização antifeminista recorre a argumentos de ordem científica e jurídica, e não propriamente religiosos e de que a linguagem da democracia é mobilizada para combater a perspectiva feminista de gênero em políticas públicas.

$\mathrm{O}$ artigo está dividido em três seçôes. A primeira seção apresenta uma revisão da literatura sobre os impasses encarados pelos movimentos feministas frente ao atual conservadorismo moral da direita emergente. $\mathrm{Na}$ segunda seção são expostos os procedimentos metodológicos de análise dos discursos e proposiçóes das deputadas. Já na terceira seção são identificados os argumentos feministas e antifeministas, bem como suas concepçóes sobre a democracia em disputa.

\section{UM PASSO ADIANTE, DOIS PASSOS ATRÁS}

Demandando reconhecimento, mudanças de valores na sociedade e denunciando violências, desigualdades e relaçóes de privilégio e subalternização, os movimentos feministas e LGBTQIA+ conquistaram uma série de direitos e promoveram transformaçóes políticas, culturais e intelectuais em diversos países (Sagot, 2012, p.75-76).

$4 \quad$ Lésbicas, gays, bissexuais, pessoas trans, queer, intersexo, assexuais e demais identidades que diferem das normas cisgênera e heterossexual. 
Os movimentos que são ferramentas de grupos historicamente subalternizados, como o feminista e LGBTQIA+, são mais que um movimento social clássico com suas grandes manifestaçôes, uma vez que também disputam sentidos e significados, como a cidadania, a democracia, a igualdade e a justiça. Tais conceitos não podem ser universalizantes, mas devem levar em consideração as particularidades e as diferenças produzidas pelas hierarquias sociais, culturais e sexuais, a fim de permitir a construção de uma sociedade que dê as condiçôes necessárias para que todos os seus membros participem das decisóes sobre suas condiçôes de vida (Sagot, 2012).

Autoras feministas latino-americanas, como a costarriquenha Montserrat Sagot (2012), argumentam ser característica dos movimentos feministas da regiáo a sua proximidade com as esquerdas, tecendo críticas tanto ao sistema de opressão de gênero como às opressões econômicas e políticas do neoliberalismo. Outra característica, ainda segundo Sagot, é a prioridade na agenda feminista da região ser a ampliação da cidadania das mulheres através da sua representação nos espaços de tomada de decisão, impulsionando a aprovação de leis, políticas públicas e transformaçôes institucionais no Estado.

O crescimento desses movimentos e sua conquista de legitimidade não passaram despercebidos pelas instituiçóes religiosas conservadoras. Os principais setores da igreja católica passaram a construir, desde meados da década de 1990, no contexto de conferências da ONU, um discurso que justifica uma contraofensiva conservadora que visa frear as conquistas de mulheres e de dissidentes sexuais e de gênero ${ }^{5}$, em especial na América Latina e na Europa (Balieiro, 2017; Corrêa, 2018).

A formulação de tal discurso foi feita por lideranças da igreja católica durante os anos 1990 e 2000, buscando refutar a compreensão feminista sobre o gênero - a compreensão de que gênero é um fenômeno cultural. Eles caracterizaram pejorativamente a teoria feminista como (1) algo radicalizado por influência do marxismo, (2) algo que ameaça a família e o matrimônio, (3) algo que incentiva a pedofilia e (4) algo que é anti-científico, uma vez que supostamente nega evidências biológicas (Corrêa, 2018; Machado, 2018).

Portanto, se observa a criação de uma estratégia discursiva no interior do Vaticano que não fala apenas de normas divinas, mas traz para o centro da argumentação a defesa da ciência, em especial a biologia, mas principalmente a suposta defesa dos direitos de um grupo vulnerável: as crianças. Segundo Fernando Figueiredo Balieiro:

A oposição a tal agenda de direitos humanos se efetuou a partir de um recurso discursivo estratégico: uma mudança na chave interpretativa na qual a expansão de direitos à população LGBT contida nas iniciativas governamentais era concebida como uma ameaça às crianças. No lugar de se apresentarem como contrários à equiparação de direitos, os agentes do pânico moral se mostraram como defensores dos direitos das crianças, enquanto seus adversários foram transformados em inimigos com presumidas intençôes ocultas que ameaçariam as bases da sociedade (Balieiro, 2018, p. 4).

O uso deste recurso discursivo estratégico, portanto, permite que a direita antifeminista receba uma aparência de defensora da democracia e dos direitos enquanto se opóe ao reconhecimento de demandas de grupos que historicamente sofrem violência e subalternização. A costarriquenha

5 Lésbicas, gays, bissexuais, travestis, transexuais, pessoas não-binárias e todo o espectro de identidades que diferem da norma heterossexual e cisgênera. 
Montserrat Sagot (2012) vai além na compreensão de tal fenômeno, mobilizando a concepção dos sociólogos da religião Enzo Pace e Renzo Guolo de neointegrismo religioso.

O neointegrismo religioso é uma estratégia discursiva que disfarça argumentos, valores e ideias religiosas com uma roupagem democrática. No discurso dos atores que mobilizam a estratégia pouco se fala de deus, da bíblia ou do pecado, enquanto a linguagem da democracia e da ciência se encontram no centro da argumentação. Sagot (2012) argumenta ser interessante para os governos das democracias neoliberais da América Latina adotar e transformar em políticas públicas o substrato moral dos posicionamentos religiosos, uma vez que o neointegrismo religioso thes serve de sustento ideológico.

O compromisso dos governantes implica defender as posiçóes que interessam aos grupos religiosos neointegristas e implementar açóes estatais nesse sentido, em troca de seu respaldo ideológico - que pode ser interpretado pelas pessoas que crêem e que precisam de fé como respaldo "divino" - para ter um terreno livre e até "santificado" para continuar com as práticas políticas e econômicas que causaram tanta desigualdade social, violência e exclusão ${ }^{6}$ (Sagot, 2012, p. 92).

Tal recurso discursivo foi adotado, portanto, para além de cristãos conservadores, também por grande parte dos movimentos de extrema-direita que emergem pelo mundo impondo a desdemocratização (Rancière, 2014).

Aqui se compreende democracia, ou processos democratizantes, como a vida democrática, "uma contestação militante permanente" (Rancière, 2014, p. 16), ou as açôes políticas operacionalizadas pela prática do dissenso, que é a atividade conflitiva que questiona e modifica o ordenamento "do mundo sensível que define [...] as formas do espaço em que o comando se exerce" (Rancière, 1996, p.372). Exemplo de prática democratizante é o avanço feminista que busca fazer com que os Estados e a populaçáo compreendam os problemas enfrentados por mulheres e pessoas que desrespeitam as normas de gênero e sexualidade como merecedores de discussão e intervenção pública.

Já os processos de desdemocratização são aqueles promovidos pela democracia neoliberal que reprimem a democracia, se queixando do povo, de seus costumes e de suas conquistas (Rancière, 2014, p. 10) e que tentam afastar a populaçáo, em especial a enorme parcela da populaçáo pertencente a grupos que foram historicamente subalternizados, da política, conferindo as decisóes à especialistas que naturalizam a expansão capitalista (Rancière, 2014, p. 99) e as normas de gênero.

No Brasil a extrema-direita neoliberal desdemocratizante, segundo Michael Lowy (2015), tem pouca relação com o integralismo dos anos 1930, não se manifesta através de partidos de massa assumidamente racistas, mas manipula demagogicamente a pauta do combate à corrupção e agita uma ideologia repressiva e policialesca, além de incitar ódio e intolerância à pessoas que desobedecem a cisheteronorma (Lowy, 2015, pp. 662-663). Ela é representada, sobretudo, pelo Bolsonarismo, fenômeno político que está além da figura de Bolsonaro e que Adriano de Freixo e Rosana Pinheiro-Machado caracterizam

6 Tradução própria para "El compromiso para los gobernantes implica defender las posiciones que le interesan a los grupos religiosos neointegristas e implementar acciones estatales en ese sentido, a cambio de su respaldo ideológico -que puede ser interpretado por el pueblo creyente y necesitado de fe como respaldo "divino"- con el fin de tener el terreno libre y hasta "santificado" para continuar con las prácticas políticas y económicas que tanta desigualdad social, violencia y exclusión han provocado”. 
por uma visão de mundo ultraconservadora, que prega o retorno aos "valores tradicionais" e assume uma retórica nacionalista e "patriótica", sendo profundamente crítica a tudo aquilo que esteja minimamente identificado com a esquerda e o progressismo (Freixo e Pinheiro-Machado, 2019, p.19).

Sendo as pautas feministas e do movimento LGBTQIA+ identificadas pelo bolsonarismo como atreladas às esquerdas e ao progressismo, o combate à chamada "ideologia de gênero" foi um tema recorrente na campanha presidencial de Jair Bolsonaro e dos candidatos de seu partido aos cargos legislativos em 2018. Não ao acaso todas as deputadas identificadas na presente pesquisa como antifeministas são do partido que elegeu Jair Bolsonaro (Partido Social Liberal).

Para analisar a argumentação das deputadas bolsonaristas antifeministas da atual legislatura, bem como a argumentação parlamentar feminista, a fim de responder a questão norteadora do trabalho de qual é a natureza e como se diferenciam os argumentos utilizados pelas parlamentares antifeministas e feministas no que diz respeito ao combate e à defesa do feminismo e dos movimentos de diferença sexual e de gênero durante o ano de 2019, foram formuladas as seguintes hipóteses: (H1) A mobilização antifeminista recorre a argumentos de ordem científica e jurídica, e não propriamente religiosos; e (H2) A linguagem da democracia é mobilizada para combater a perspectiva feminista de gênero em políticas públicas. A próxima seção trata dos procedimentos metodológicos utilizados para se alcançar tal fim e para testar as hipóteses formuladas.

\section{PROCEDIMENTOS METODOLÓGICOS}

Logo após ser divulgado o resultado eleitoral de 2018, diversos jornais e portais de notícias passaram a publicar textos acerca do crescimento da representação feminina na Câmara dos Deputados e em várias Assembleias Legislativas. Porém, grande parte das notícias questionava se tal crescimento de fato se efetivaria em avanços nas políticas públicas específicas para as mulheres, uma vez que parte significativa das eleitas é pertencente a grupos de direita e extrema-direita antifeministas.

A fim contribuir com o debate sobre a atual representação feminina e o conservadorismo, se buscou identificar os argumentos mobilizados por deputadas federais da atual legislatura no combate às pautas feministas e de gênero na Câmara dos Deputados. Foram analisados os discursos em plenário e as justificativas de proposições legais submetidas por mulheres no ano de 2019, mobilizando uma abordagem qualitativa a partir da Análise de Conteúdo categorial com aplicação de teste de confiabilidade para a categorização.

A coleta de dados foi realizada até o final de outubro de 2019 na plataforma de monitoramento legislativo inteligente SigaLei ${ }^{7}$ através de busca das palavras-chave "ideologia de gênero", "LGBT" e "aborto". As palavras-chave foram escolhidas por serem os temas mais explorados pela bibliografia sobre o atual conservadorismo moral no Brasil (Almeida, 2017; Balieiro, 2017; Machado, 2016; Machado, 2018; Miguel et al, 2017).

Após a exclusão dos discursos e proposiçôes que mobilizam o feminismo apenas como um tema tangente, foram selecionados para análise 13 proposiçóes e 11 discursos, que foram classificados 
inicialmente entre antifeministas - aqueles que combatem a concepção feminista de gênero - e feministas - aqueles que levantam a discussão sobre gênero ou que se opóem às antifeministas. Foram classificadas 9 proposiçóes e 7 discursos como antifeministas e 4 proposiçóes e 4 discursos como feministas, como mostram a Tabela 1 e a Tabela 2.

Tabela 1 - Proposições submetidas por mulheres feministas e antifeministas em 2019

\begin{tabular}{|c|c|c|c|}
\hline Proposição & Autora principal & Partido (UF) & Categoria \\
\hline REQ 11/2019 & Chris Tonietto & PSL (RJ) & Antifeminista \\
\hline REQ 4/2019 & Chris Tonietto & PSL (RJ) & Antifeminista \\
\hline INC 1225/2019 & Chris Tonietto & PSL (RJ) & Antifeminista \\
\hline RIC 1043/2019 & Chris Tonietto & PSL (RJ) & Antifeminista \\
\hline PL 2893/2019 & Chris Tonietto & PSL (RJ) & Antifeminista \\
\hline INC 1063/2019 & Chris Tonietto & PSL (RJ) & Antifeminista \\
\hline PL 4150/2019 & Chris Tonietto & PSL (RJ) & Antifeminista \\
\hline PL 3492/2019 & Carla Zambelli & PSL (SP) & Antifeminista \\
\hline PL 4149/2019 & Chris Tonietto & PSL (RJ) & Antifeminista \\
\hline REQ 15/2019 & Paula Belmonte & PPS (DF) & Feminista \\
\hline REQ 36/2019 & Sâmia Bomfim & PSOL (SP) & Feminista \\
\hline RIC 1505/2019 & Talíria Petrone & PSOL (RJ) & Feminista \\
\hline PL 1189/2019 & Natália Bonavides & PT (RN) & Feminista \\
\hline
\end{tabular}

Fonte: elaboração própria através de dados coletados no SigaLei.

Tabela 2 - Discursos proferidos por mulheres feministas e antifeministas em 2019

\begin{tabular}{|c|c|c|c|}
\hline Deputada & Partido (UF) & Data e Horário & Categoria \\
\hline Chris Tonietto & PSL (RJ) & $04 / 07 / 201915: 08$ & Antifeminista \\
\hline Bia Kicis & PSL (DF) & $12 / 06 / 201918: 32$ & Antifeminista \\
\hline Bia Kicis & PSL (DF) & $07 / 02 / 201916: 12$ & Antifeminista \\
\hline Chris Tonietto & PSL (RJ) & $07 / 02 / 201916: 04$ & Antifeminista \\
\hline Chris Tonietto & PSL (RJ) & $05 / 02 / 201918: 44$ & Antifeminista \\
\hline Chris Tonietto & PSL (RJ) & $10 / 10 / 201916: 48$ & Antifeminista \\
\hline Chris Tonietto & PSL (RJ) & $03 / 10 / 201916: 36$ & Antifeminista \\
\hline Sâmia Bomfim & PSOL (SP) & $03 / 09 / 201919: 12$ & Feminista \\
\hline Talíria Petrone & PSOL (RJ) & $03 / 09 / 201917: 48$ & Feminista \\
\hline Jandira Feghali & PCdoB (RJ) & $03 / 09 / 201919: 24$ & Feminista \\
\hline Talíria Petrone & PSOL (RJ) & $03 / 09 / 201918: 52$ & Feminista \\
\hline
\end{tabular}

Fonte: elaboração própria através de dados coletados no SigaLei.

O método adotado para o exame dos discursos e das proposiçóes legais foi a Análise de Conteúdo, conjunto de técnicas para análise de comunicaçôes que visam obter, através de 
procedimentos sistemáticos, indicadores que permitam realizar inferência de conhecimentos (Bardin, 2009; Cavalcante et al, 2014), possibilitando a descrição das mensagens atreladas ao seu contexto.

Após a leitura dos discursos e proposiçôes feministas e antifeministas selecionadas, foram retiradas as citaçôes diretas feitas pelas parlamentares nos dois tipos de materiais, bem como foram excluídos os trechos dos discursos que não tratavam do embate entre feministas e antifeministas. Os argumentos encontrados foram categorizados, com o auxílio do software NVivo, em sua versão de teste gratuita, através das seguintes categorias:

- Democracia: Argumentos que fazem um apelo ao majoritarismo ou opinião pública. Defesa de direitos de minorias como mulheres e crianças. Denúncias acerca de crise democrática ou desdemocratização, bem como o desequilíbrio entre os Poderes e a usurpação do Poder Legislativo pelo Judiciário ou Executivo. Denúncias de censura ou de doutrinaçóes. Demanda pela liberdade de pensamento e autonomia. Exemplo: "O fato é que esses grupos minoritários - mas extremamente barulhentos - há anos vêm cerceando o direito dos individuos expressarem livremente sua opiniāo, quando discordante da realidade paralela idealizada por eles"

- Jurídico: Argumentação acerca do ordenamento legal, das leis, das normativas, do descumprimento de alguma norma, das hierarquias entre normativas e da interpretação de uma legislação. Exemplo: "A Constituição Federal, em seu artigo 50, estabelece, como um dos seus princípios basilares, o direito inviolável à vida, sendo certo que o Código Civil Brasileiro (Lei no 10.406/2002) dispóe, em seu artigo $2^{\circ}$, que a lei póe a salvo, desde a concepção, os direitos do nascituro"

- Científico: Mobilização de dados, autores e teorias - aceitas na comunidade científica ou não. Desqualificação ou rejeição de uma teoria. Acusação de negar a verdade ou a realidade. Exemplo: "Ocorre que não há dúvida quanto ao marco inicial da vida humana que, por evidência cientifica, começa na concepção"

- Religioso: Argumentação que mobiliza dogmas religiosos ou que defendam leis divinas. Acusação de fundamentalismo.

Exemplo: "É por isso que me propus desde o início - e mantenho este compromisso - a: primeiro, combater qualquer iniciativa ou projeto de lei abortista ou que procure atacar a familia e os valores cristãos da sociedade"

Para demonstrar as distintas e conflitantes concepçóes de democracia presentes na argumentação das parlamentares, a categoria "Democracia" foi subdividida nas seguintes subcategorias:

- Majoritarismo: Argumentos que expressam a ideia de que maioria cristá deve prevalecer sobre a minoria. Mobilização da opinião pública. Denúncia sobre a suposta demanda por privilégios por parte de minorias políticas. 
Exemplo: "Torno a dizer: estamos no Parlamento brasileiro. Representamos a vontade popular. A maioria da população brasileira é pró-vida, ou seja, rejeita maciçamente o aborto. Mas por que eles insistem em pautar esse tipo de matéria no Supremo, à revelia deste Parlamento?”

-Usurpaçãolegislativa:Denúncias sobreum supostodesequilíbriodosPoderesesobreo "ativismo judicial”. Demonstração acerca da não omissão legislativa sobre demandas de minorias políticas. Exemplo: "O que é, então, o ativismo judicial? É a usurpação de competência levada a efeito, muitas vezes, pelos Ministros do Supremo Tribunal Federal. É a invasão, é o atropelo na função tipica de legislar"

- Minorias: Defesa de direitos de mulheres, população LGBTQIA+ e pessoas negras. Busca por redução das desigualdades, de violências e preconceitos contra tais grupos através de políticas de mudança de cultura política.

Exemplo: "Querer proibir o que chamam de ideologia de gênero na escola é impedir a escola de ser um instrumento para romper a extrema violência sexual que vitima muitas adolescentes, violência que parte da própria familia"

- Criança: Demanda por direitos de fetos, proteção dos direitos das crianças e denúncias de suposta doutrinação em escolas. Denúncias acerca de suposta sexualização de crianças. Posicionamentos contra a pedofilia. Defesa da educação como tarefa da família. Exemplo: "Chamar atenção para o imenso perigo de sua aceitação e aprovação é dever ao qual não se pode furtar. Neste mesmo sentido, deve-se denunciar sempre, dentre outras, a ideologia de gênero, que incentiva a pedofilia pela sexualizaçâo precoce das crianças"

- Desdemocratização: Demanda pela cidadania, liberdade de pensamento e autonomia. Denúncias de censura. Corrosáo de pilares da sociedade. Denúncia acerca da suposta perseguição a grupos ou à uma determinada forma de pensar. Trato de adversários políticos como inimigos.

Exemplo: "A garantia da estabilidade social depende, em grande parte, da manutenção das instituiçôes de base que precedem a constituição do Estado. A primeira delas é a família, origem histórica da pólis e fundamento antropológico das leis"

A fim de demonstrar a confiabilidade da categorizaçáo executada (Sampaio e Lycariao, 2018), foi realizado, a partir da ferramenta gratuita $\mathrm{ReCal}^{8}$ (Freelon, 2017), um teste de confiabilidade entre duas categorizadoras. Assim, foi calculada a concordância percentual de 76,5\% e um coeficiente de concordância Kappa de 0.623, identificado como forte/substancial.

Na seção seguinte serão apresentadas as análises dos resultados encontrados.

\section{RESULTADOS E DISCUSSÃO}

Em conjunto, as proposiçóes submetidas pelas parlamentares antifeministas procuram (1) criar propaganda contra a descriminalização do aborto'; (2) criminalizar o aborto em todos os casos ${ }^{10}$; (3) promover censura a uma pesquisa sobre saúde sexual LGBT ${ }^{11}$; (4) promover censura a atividades

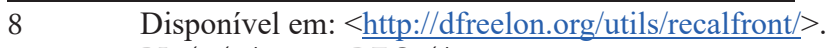

$9 \quad$ PL 4149/2019 e REQ 4/2019.

$10 \quad$ PL 2893/2019 e PL 4150/2019.

11 INC $1225 / 2019$. 
políticas e discussão de livros feministas no Colégio Pedro $\mathrm{II}^{12} ;(5)$ criar propaganda que atrela a discussão sobre gênero à pedofilia ${ }^{13}$; (6) retirar o termo "gênero" e a expressão "famílias diversas" de materiais de programas institucionais ${ }^{14}$; e (7) criminalizar a possibilidade de assassinato para imposição de transgeneridade ${ }^{15}$.

Em contrapartida, as proposiçóes submetidas pelas parlamentares feministas buscam (1) realizaçâo de audiência pública sobre a retirada de questôes sobre gênero no $\operatorname{ENEM}^{16}$; (2) informaçôes sobre a atual política de aborto legal e sobre políticas de educação sexual ${ }^{17}$; (3) cobrar posicionamento frente a movimentos que tentam impedir o acesso da população aos serviços de aborto legal ${ }^{18}$; (4) realização de audiência pública sobre a atual política de aborto legal ${ }^{19}$; e (5) promover a discussão nas escolas sobre temas relativos a raça e etnia, religião, gênero, identidade de gênero, orientação sexual, pessoas com deficiência, entre outros ${ }^{20}$.

Como mostra a Tabela 3, mais da metade dos argumentos mobilizados, tanto pelas antifeministas quanto pelas feministas, são de ordem democrática, enquanto os argumentos religiosos aparecem apenas de forma minoritária. Os dados sugerem a aceitação das hipóteses, apontando que a mobilização antifeminista recorre a argumentos de ordem científica e jurídica, e não propriamente religiosos e que a linguagem da democracia é mobilizada para combater a perspectiva feminista de gênero em políticas públicas.

Tabela 3 - Argumentação das deputadas feministas e antifeministas em 2019

\begin{tabular}{|c|c|c|c|c|}
\cline { 2 - 5 } \multicolumn{1}{c|}{} & \multicolumn{2}{c|}{ Antifeministas } & \multicolumn{2}{c|}{ Feministas } \\
\hline Categoria & Argumentos & $\%$ & Argumentos & $\%$ \\
\hline Democracia & 107 & $54,87 \%$ & 28 & $53,85 \%$ \\
\hline Jurídico & 50 & $25,64 \%$ & 11 & $21,15 \%$ \\
\hline Científico & 35 & $17,95 \%$ & 12 & $23,08 \%$ \\
\hline Religioso & 3 & $1,54 \%$ & 1 & $1,92 \%$ \\
\hline Total & 195 & $100 \%$ & 52 & $100 \%$ \\
\hline
\end{tabular}

Fonte: elaboração própria com o auxílio do NVivo através de dados coletados no SigaLei.

A pouca variação dos percentuais das categorias de argumentos não significa que os discursos feministas e antifeministas sejam semelhantes. Pelo contrário, os dados indicam um antagonismo e disputa entre as concepções de democracia mobilizadas, como evidenciam a Tabela 4 e as nuvens com as 30 palavras mais frequentes nas argumentaçôes antifeminista e feminista, que foram elaboradas com o auxílio do software NVivo e que são expostas nas figuras 1 e 2 .

\begin{tabular}{ll}
\hline 12 & INC $1063 / 2019$. \\
13 & REQ $11 / 2019$. \\
14 & RIC $1043 / 2019$ \\
15 & PL $3492 / 2019$ \\
16 & REQ $15 / 2019$ \\
17 & RIC $1505 / 2019$ \\
18 & RIC $1505 / 2019$ \\
19 & REQ $36 / 2019$ \\
20 & PL $1189 / 2019$.
\end{tabular}


$\mathrm{Na}$ argumentação antifeminista se encontram quatro grandes preocupaçóes com a democracia: (1) a demanda pelo reconhecimento de direitos fundamentais e de personalidade ao feto; (2) a suposta doutrinação e sexualização de crianças promovida pelas feministas e pelo movimento LGBTQIA+; (3) a alegação de que o Supremo Tribunal Federal, ao decidir sobre aborto e criminalização da LGBTfobia, fere a democracia por supostamente usurpar o Poder Legislativo; e (4) a crença de que a vontade da maioria cristã deva prevalecer sobre os direitos de minorias políticas como mulheres e a populaçáo LGBTQIA+.

A demanda pelo reconhecimento de direitos dos fetos, sob a premissa do direito à vida desde a concepção, é o principal argumento mobilizado pelos atores que demandam um recrudescimento da criminalização do aborto (Miguel et al, 2017). O "direito à vida" aparece no discurso antifeminista analisado sob argumentos de ordem democrática, alegando usurpaçáo de Poderes Legislativos por parte do Judiciário e, portanto, indicando um desequilíbrio entre os três Poderes; de ordem jurídica, mobilizando o Artigo $5^{\circ}$ da Constituição Federal ${ }^{21}$ e o Artigo $2^{\circ}$ do Código Civil ${ }^{22}$; e de ordem religiosa, mobilizando o quinto mandamento da lei do deus cristão - "Não matarás".

Tabela 4 - Argumentação sobre democracia das deputadas antifeministas e feministas em 2019

\begin{tabular}{|c|c|c|c|c|}
\cline { 2 - 5 } \multicolumn{1}{c|}{} & \multicolumn{2}{c|}{ Antifeministas } & \multicolumn{2}{c|}{ Feministas } \\
\hline Subcategoria & Argumentos & $\%$ & Argumentos & $\%$ \\
\hline Majoritarismo & 18 & 16,82 & 0 & 0 \\
\hline $\begin{array}{c}\text { Usurpação } \\
\text { legislativa }\end{array}$ & 30 & 28,04 & 0 & 0 \\
\hline Minorias & 4 & 3,74 & 20 & 71,43 \\
\hline Crianças & 39 & 36,45 & 2 & 7,14 \\
\hline Desdemocratização & 10 & 9,34 & 6 & 21,43 \\
\hline Outros & 6 & 5,61 & 0 & 0 \\
\hline Total & 107 & $100 \%$ & 28 & $100 \%$ \\
\hline
\end{tabular}

Fonte: elaboração própria com o auxílio do NVivo através de dados coletados no SigaLei.

O objetivo do uso do argumento do "direito à vida desde a concepção" é submeter os direitos sexuais e reprodutivos de mulheres, homens trans e pessoas não-binárias que podem engravidar à expectativa de direitos de seres não nascidos, promovendo o recrudescimento da criminalizaçáo do aborto e privando milhares de pessoas pertencentes a esses grupos historicamente subalternizados do direito ao aborto legal, seguro e gratuito.

A suposta doutrinação e sexualização de crianças promovida pelas feministas e pelo movimento LGBTQIA+, mobilizada sempre sob uma argumentação sobre democracia, é o principal recurso para frear os avanços aos direitos sexuais e reprodutivos (Balieiro, 2018). O objetivo aqui é impedir que o Estado passe a reconhecer a necessidade de que a populaçáa aprenda desde cedo, na escola, que lésbicas, gays, bissexuais e pessoas trans são tão dignas de respeito e direitos quanto aqueles que se encaixam nas normas cisgênera e heterossexual.

21 Art. $5^{\circ}$ Todos são iguais perante a lei, sem distinção de qualquer natureza, garantindo-se aos brasileiros e aos estrangeiros residentes no País a inviolabilidade do direito à vida, à liberdade, à igualdade, à segurança e à propriedade.

22 Art. $2^{\circ}$ A personalidade civil da pessoa começa do nascimento com vida; mas a lei póe a salvo, desde a concepção, os direitos do nascituro. 
Figura 1- 30 palavras mais frequentes na argumentação antifeminista

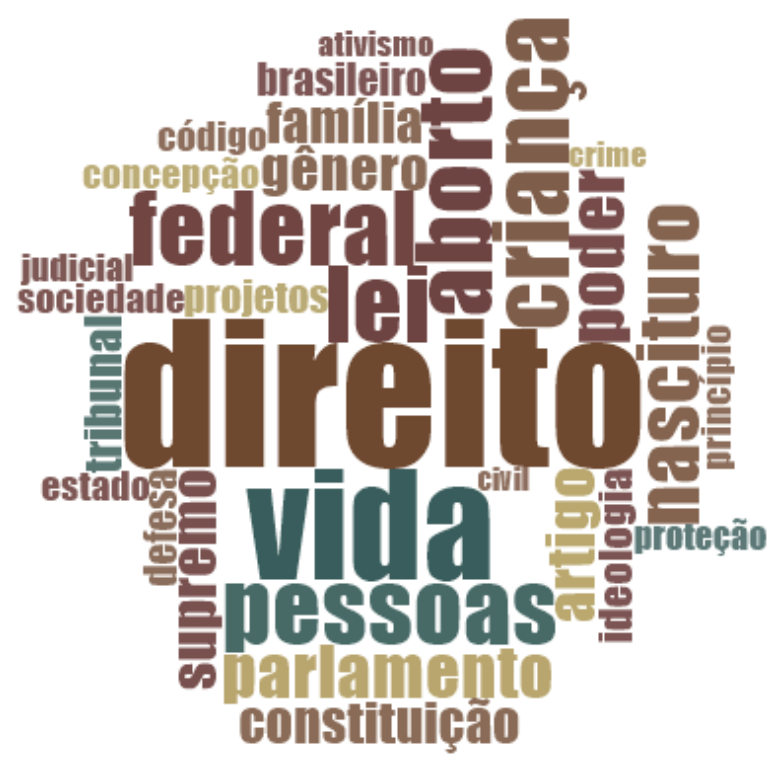

Fonte: elaboração própria com o auxílio do NVivo através de dados coletados no SigaLei.

Sob a alegação de suposto ativismo judicial por parte Supremo Tribunal Federal as deputadas antifeministas demonstram seu descontentamento com a Arguição de Descumprimento de Preceito Fundamental (ADPF) 54, que descriminalizou o aborto em caso de anencefalia do feto; com a Ação Direta de Inconstitucionalidade (ADI) 5.581, que defende a descriminalizaçáo do aborto em casos de gestante infectada com o "zika vírus"; com a ADPF 442, que pede a descriminalização do aborto até a $12^{a}$ semana de gestação; e com a Ação Direta de Inconstitucionalidade por Omissão (ADO) 26, que reconheceu a omissão legislativa e enquadrou a LGBTfobia como crime de racismo.

Argumentos que acompanham as denúncias de ativismo judicial são os de apelo à opinião pública, alegando que o povo elegeu um Congresso que não descriminaliza o aborto e que não criminaliza a LGBTfobia porque a maioria da populaçáo é cristã, contra o aborto e contra a discussão sobre gênero nas escolas. Aqui nota-se forte apelo ao majoritarismo, ou seja, a premissa que deve prevalecer a vontade de uma determinada maioria diante da minoria, colidindo com princípios edificantes da democracia liberal (O’Donnell, 1998).

A argumentação feminista levanta duas principais preocupaçôes com a democracia: (1) a defesa de uma educação emancipadora e (2) a violência contra as mulheres e a proteção de direitos de minorias políticas. As duas preocupaçóes estão intimamente ligadas, uma vez que a escola seria o local do aprendizado acerca do respeito às diferenças e busca por igualdade jurídica e social, reparando injustiças e preconceitos contra minorias políticas como mulheres, povo negro e população LGBTQIA+. 
Figura 2 - 30 palavras mais frequentes na argumentação feminista

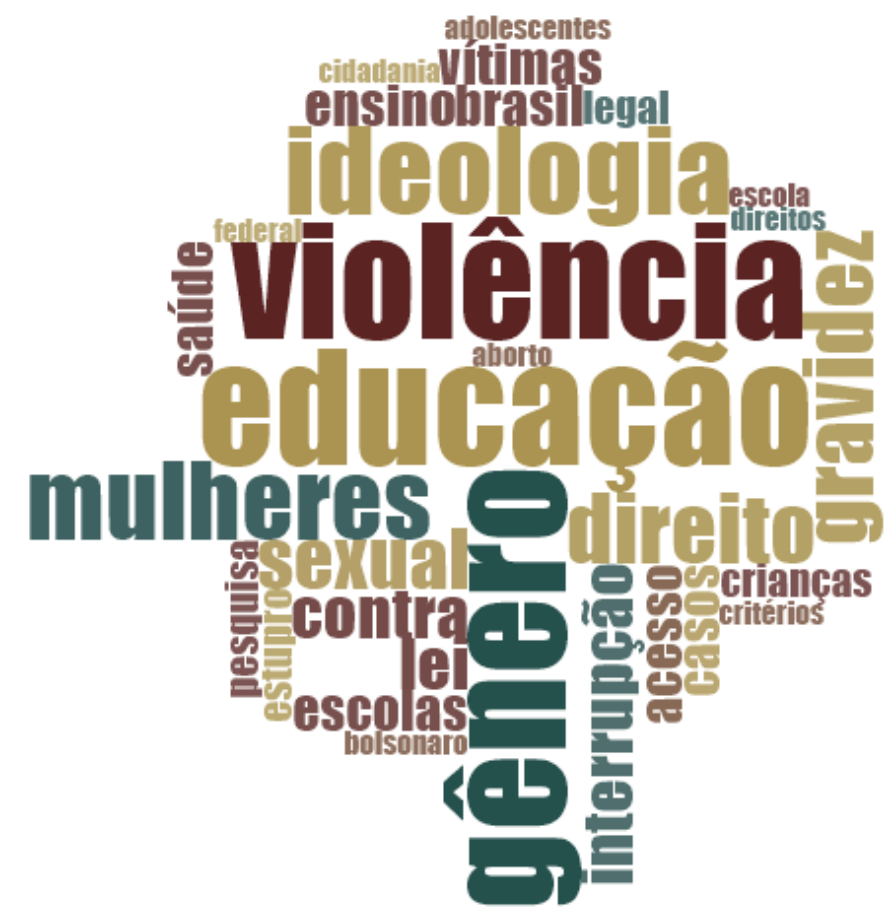

Fonte: elaboração própria com o auxílio do NVivo através de dados coletados no SigaLei.

Além da defesa de minorias políticas através da educação, as feministas também procuram responder aos argumentos daqueles que combatem o feminismo e as pautas de gênero e sexualidade, argumentando que "ideologia de gênero" (1) não existe; (2) é uma categoria que cria confusão perante a sociedade; e (3) impede que a escola seja um instrumento de combate a violências. Isso demonstra que as mulheres feministas e de esquerda não se furtam ao debate sobre feminismo e sobre o fantasma da "ideologia de gênero" na atual legislatura e promovem o embate frente a desdemocratização promovida pelos grupos antifeministas de direita.

\section{CONSIDERAÇÕES FINAIS}

$\mathrm{O}$ artigo identificou que existem concepções de democracia em disputa nas argumentações das deputadas antifeministas e feministas. O majoritarismo é algo central na concepçáo democrática das antifeministas. Uma vez que a maioria da população brasileira é cristâ, contra o aborto e contra o debate sobre gênero e sexualidade nas escolas, as minorias não teriam o direito nem mesmo a buscar instâncias como o Supremo Tribunal Federal para recorrer aos seus direitos. Já para as feministas, o uso das escolas como instrumento de mudança de cultura política a fim de combater preconceitos e violências contra minorias políticas se encontra no centro da concepçáo de democracia.

Os dados suportam as hipóteses, apontando que a mobilização antifeminista recorre a argumentos de ordem científica e jurídica, e não propriamente religiosos e que a linguagem da democracia é mobilizada para combater a perspectiva feminista de gênero em políticas públicas e para impedir a cidadania feminina e LGBTQIA+. 
Uma das preocupaçóes iniciais do artigo foi se o crescimento da "Bancada Feminina" de fato se efetivaria em avanços nas políticas públicas específicas para as mulheres, uma vez que parte significativa das eleitas é pertencente a grupos de direita e extrema-direita antifeministas.

Os dados apontam que as posiçóes feministas são minoritárias e se encontram diante do impasse de ver suas pautas sendo concebidas pelo grande público como uma ameaça à democracia e à sociedade, uma vez que os atores da direita antifeminista utilizam um recurso discursivo estratégico de transformar os empreendimentos feministas em doutrinação, sexualização e assassinatos de crianças, ainda que não nascidas. Desta forma se torna mais difícil combater o avanço conservador antifeminista, uma vez que valores cristáos conservadores são camuflados com uma aparência democrática e a debilitação do caráter laico do Estado não é percebida.

\section{REFERÊNCIAS}

ALMEIDA, Ronaldo de. A onda quebrada - evangélicos e conservadorismo. Cadernos Pagu, Campinas, n. 50, 2017. Disponível em: <http://www.scielo.br/pdf/cpa/n50/1809-4449-cpa-18094449201700500001. pdf $>$. Acesso em: 11/11/2018.

BALIEIRO, Fernando de Figueiredo. A "guerra" contra o gênero: reaçóes às últimas décadas de políticas de promoção da igualdade de gênero no Brasil. Cadernos Pagu, Campinas, n. 51, 2017. Disponível em: $<\underline{\text { ht- }}$ tp://www.scielo.br/pdf/cpa/n51/1809-4449-cpa-18094449201700510022.pdf>. Acesso em: 10/11/2018.

. "Não se meta com meus filhos": a construção do pânico moral da criança sob ameaça. Cadernos

Pagu, Campinas, n. 53, 2018. Disponível em: <http://www.scielo.br/pdf/cpa/n53/1809-4449-cpa-18094449201800530006.pdf>. Acesso em: 02/02/2019.

BARDIN, L. Análise de Conteúdo. Lisboa, Portugal; Ediçóes 70, LDA, 2009.

CAVALCANTE, Ricardo B.; CALIXTO, Pedro; PINHEIRO, Marta M. K. Análise de conteúdo: consideraçóes gerais, relaçôes com a pergunta de pesquisa, possibilidades e limitaçóes do método. Inf. \& Soc.: Est., João Pessoa, v24, n.1, p. 13-18, 2014. Disponível em: <https://periodicos.ufpb.br/ojs2/index.php/ies/ article/view/10000/10871>. Acesso em: 02/10/2019,

CORRÊA, Sonia. A "política do gênero": um comentário genealógico. Cadernos Pagu, Campinas, n. 53, 2018. Disponível em: <http://www.scielo.br/pdf/cpa/n53/1809-4449-cpa-18094449201800530001.pdf>. Acesso em: 02/02/2019.

FREELON, D. ReCal: reliability calculation for the masses. Washington, 2017. Ferramenta on-line atualizada em 22 maio 2017. Disponível em: <http://dfreelon.org/utils/recalfront/>. Acesso em 30/10/2019.

FREIXO, Adriano de; PINHEIRO-MACHADO, Rosana. "Dias de um futuro (quase) esquecido: um país em transe, a democracia em colapso" In: PINHEIRO-MACHADO, Rosana; FREIXO, Adriano de. Brasil em transe: Bolsonarismo, Nova direita e Desdemocratização. Rio de Janeiro: Oficina Raquel, 2019, p. 09-24.

LEVITSKY, Steven; ZIBLATT, Daniel. Como as democracias morrem. Rio de Janeiro: Zahar, 2018. 
LOWY, Michel. Conservadorismo e extrema-direita na Europa e no Brasil. Serviço Social e Sociedade. São Paulo, n. 124, p. 652-664, out./dez. 2015. Disponível em: <http://www.scielo.br/pdf/sssoc/n124/ 0101-6628-sssoc-124-0652.pdf>. Acesso em: 07/05/2019.

MACHADO, Maria das Dores Campos. Política, direitos humanos e aborto: uma análise das opiniōes de líderes pentecostais brasileiros. In: BIROLI, Flávia \& MIGUEL, Luís Felipe (orgs.), Aborto e Democracia, São Paulo: Alameda, pp. 85-106, 2016.

. O discurso cristão sobre a "ideologia de gênero". Revista Estudos Feministas, Florianópolis, v. 26, n. 2, 2018. Disponível em: <http://www.scielo.br/pdf/ref/v26n2/1806-9584-ref-26-02-e47463.pdf>. Acesso em: 12/01/2019.

MARIANO, Ricardo. Laicidade à brasileira. Católicos, pentecostais e laicos em disputa na esfera pública. Civitas - Revista de Ciências Sociais, v. 11, n. 2 maio-ago, p. 238-258, 2011. Disponível em: <http:// revistaseletronicas.pucrs.br/ojs/index.php/civitas/article/view/9647/6619>. Acesso em: 05/04/2014.

MIGUEL, L. F.; BIROLI, F; MARIANO, R. O direito ao aborto no debate legislativo brasileiro: a ofensiva conservadora na Câmara dos Deputados. Opiniáo Pública, Campinas, vol. 23, no 1, jan. - abr., 2017. Disponível em: <http://www.scielo.br/pdf/op/v23n1/1807-0191-op-23-1-0230.pdf>. Acesso em: $01 / 12 / 2018$.

NVIVO. Software de análise qualitativa (versão de teste gratuita). Disponível em: $<\underline{\text { https://www.qsrinterna- }}$ tional.com/nvivo/homes.

O 'DONNELL, Guillermo. Accountability horizontal e novas poliarquias. Lua Nova, São Paulo, n. 44, p. 27-54, 1998. Disponível em: <http://www.scielo.br/pdf/ln/n44/a03n44>. Acesso em: 20/08/2019.

QUADROS, Marcos Paulo dos Reis; MADEIRA, Rafael Machado. Fim da direita envergonhada? Atuação da bancada evangélica e da bancada da bala e os caminhos da representação do conservadorismo no Brasil. Opin. Pública, Campinas, v. 24, n. 3, p. 486-522, 2018. Disponível em: <http://www.scielo.br/pdf/op/ v24n3/1807-0191-op-24-3-0486.pdf>. Acesso em: 30/11/2019.

RANCIÈRE, Jacques. "O Dissenso". In: NOVAES, Adauto et al (org.), A Crise da Razão, São Paulo: Companhia das Letras, Brasília: MinC, Rio de Janeiro: Funarte, 1996.

. O ódio à democracia. São Paulo: Boitempo, 2014.

SAGOT, Montserrat. ¿Un paso adelante y dos atrás? La tortuosa marcha del movimiento feminista en la era del neointegrismo y del "fascismo social" en Centroamérica. In: CAROSIO, Alba (org.). Feminismo y cambio social en América Latina y el Caribe, Buenos Aires: CLACSO, pp. 75-100, 2012. Disponível em:

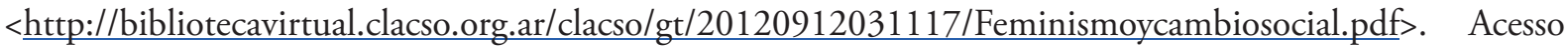
em: 06/08/2017.

SAMPAIO, Rafael; LYCARIAO, Diógenes. Eu quero acreditar! Da importância, formas de uso e limites dos testes de confiabilidade na Análise de Conteúdo. Rev. Sociol. Polit., Curitiba , v. 26, n. 66, p. 31-47, Junho de 2018. Disponível em: <http://www.scielo.br/pdf/rsocp/v26n66/0104-4478-rsocp-26-66-0031. pdf>. Acesso em: 02/11/2019.

SIGALEI. Plataforma de monitoramento legislativo inteligente. Disponível em: <https://sigalei.com.br/>. 